\title{
Numerical and experimental results of a novel and generic methodology for energy performance evaluation of thermal systems using renewable energies
}

3

\author{
Amine Lazrak ${ }^{\mathrm{a}, \mathrm{b}, \mathrm{c}}$, Antoine Leconte $^{\mathrm{b}}$, David Chèze $^{\mathrm{b}}$, Gilles Fraisse $^{\mathrm{c}}$, Philippe Papillon $^{\mathrm{b}}$, Bernard Souyri $^{\mathrm{c}}$
}

4

5

6

7

ABSTRACT

At present there is no reliable approach to model and characterize thermal systems using renewable energy for building applications based on experimental data. The results of the existing approaches are valid only for specific conditions (climate type and thermal building properties). The aim of this paper is to present a generic methodology to evaluate the energy performance of such systems. Artificial neural networks (ANNs) have proved to be suitable to tackle such complex problems, particularly when the system to be modelled is compact and cannot be divided up during the testing stage. Reliable "black box" ANN modelling is able to identify global models of the whole system without any advanced knowledge of its internal operating principles. The knowledge of the system's global inputs and outputs is sufficient. The proposed methodology is applied to evaluate three different Solar Combisystems (SCSs) combined with a gas boiler or a heat pump as an auxiliary system. The ANN models developed were able to predict, with a satisfactory degree of precision, the annual energy consumption of the systems in different conditions, based on a learning sequence lasting only 12 days. Annual energy prediction errors using the artificial neural models were less than $10 \%$ in most cases. Perspectives and methodology limitations are discussed as well.

\section{KEY-WORDS}




\begin{tabular}{|llll|}
\hline Nomenclature & & Nomenclature & \\
DHW & Domestic hot water & $P_{d h w}$ & DHW energy rate demand \\
ANN & Artificial neural networks & $A . G$ & Solar irradiation on the collector plane \\
SH & Space heating & $P_{s h}$ & SH energy rate demand \\
SC & Space cooling & $P_{a u x}$ & Auxiliary system energy rate (HP or \\
AF & Activation function & & gas boiler input) \\
HP & Heat pump & Auxiliary system energy rate model \\
SCS & Solar Combisystem & prediction \\
RETS & Renewable energy thermal systems & BIC & Bayesian information criterion \\
SCSPT & Short cycle system performance test & \\
CTSS & Component testing and system simulation & \\
CCT & Concise cycle test & \\
DST & Dynamic system testing & \\
SFH & Single family house & \\
SCSASHP & Solar Combisystem combined with an air source heat pump & \\
SCSWSHP & Solar Combisystem combined with a water source heat pump & \\
SCSGB & Solar Combisystem combined with a gas boiler & \\
\end{tabular}

\section{3}

\section{Introduction}

Today's thermal systems for building applications mix an increasing number of energy sources, some of which are available intermittently. Moreover, more and more systems are multi-functional. They can be used for domestic hot water (DHW) preparation, space heating ( $\mathrm{SH}$ ) and space cooling (SC). Several studies were conducted to investigate and demonstrate the feasibility and efficiency of renewable energy thermal systems (RETSs) to save energy in buildings [1-6] (SCSs combined with heat pump) and [7-10] (SCSs combined with a non-renewable energy source auxiliary system). It has already been observed that some of them have reached very good performance by saving up to 50\% of the auxiliary energy [11]. Unfortunately, this good performance is not met by every system installed. In fact, RETS behaviour is highly dependent on the climatic conditions and building quality (boundary conditions) [11-13]. This is why systems could have poor energy performance in some environments. For this reason it becomes necessary that users could have reliable information about the long-term performance of the system in the wanted boundary conditions.

The existing methods for SCS performance evaluation and testing can be classified into two categories, depending on their approach to evaluating primary energy savings: the component approach and the global approach. Methods that are based on the component approach, such as the Component Testing System Simulation (CTSS) [14-17], the BIN [18-19] methods, consist in separately testing the main Solar Combisystem components (heat store, controllers, thermal collector, heat pump, etc.) according to existing standard tests. Depending on the standard used it could be stationary or dynamic (a review of the existing standards could be found in [20-21]). Following the tests, the physical model parameters of each component are identified. The models are then used within thermal simulation software, such as TRNSYS, to estimate the overall annual system performance. On the one hand this approach has the advantage of being able to test any system in different configurations. Using this approach, it is also possible to conduct a design study and system performance evaluation in different boundary conditions. On the other hand, this approach has four main drawbacks:

- It takes a great deal of time and therefore the whole set of tests is expensive.

- It is limited to components whose physical models are available and their parameters need to be possible to identify with the available experimental data.

- It does not allow checking real system controls and interactions between components since they are only simulated. 
49 Contrary to the component approach, the global approach consists in testing the whole system (all components except the thermal collector and ground heat exchanger) on a semi-virtual test bench. The Short Cycle System Performance Test (SCSPT), Combitest [22], Concise Cycle Test (CCT) [23] and Dynamic System Testing DST [24], [25], [26] are examples of this kind of method. The system is charged and discharged according to a specific standard (the case of DST) or test sequence (12 days for SCSPT and CCT, but only 6 days for Combitest) particular to each method. This kind of approach ensures that all system functions and interactions (including control logics) are taken into account during the test. Modern systems are often compact and are increasingly prefabricated and assembled at the factory and manufacturers do not divulgate all the specifications of their products such as efficiency of each component and internal physical features, some examples are in Figure 1. Therefore, it is difficult to extract a sub-system from the overall system to test it without degrading the whole system. For all these reasons the global approach methods based on dynamic short tests are more relevant.
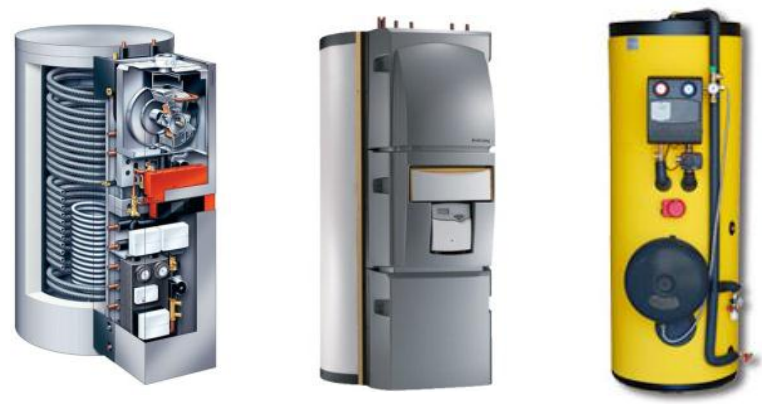

Figure. 1: Examples of some Solar Combisystems available on the market. They are commercialized by, from left to right, Viessmann, De Dietrich and

The Combitest and SCSPT use direct extrapolation from the test results to annual energy consumption (multiplication of the test results with 365/6 or 365/12, respectively). The procedure for the CCT and DST method is not based on direct extrapolation, but rather on fitting a global model (usually TRNSYS software) and simulation, as in the component approach. Further detail on the comparison of the three first methods is given in [23]. annual simulations on the basis of the identified parameter values for the model. For the SCSPT, an extrapolation procedure [27] was developed at CEA INES, France: The data measured are used to identify a dynamic simplified model of the whole system. The simplified model, called the "grey box model", combines simplified physical equations (collectors, building, storage, auxiliary = "white box") and an artificial neural network ANN ("black box"). Once the simplified model has been selected and validated, it can be used for various boundary conditions (collector area, building and climate) in order to obtain annual results. Extrapolation to other boundary conditions using these methods is based, at least in part, on physical models. The development of such models is not usually easy. In fact, internal components (storage, regulation system or any other specific system) may be unknown especially because systems are often compact. Besides, the reliability of the results depends a great deal on the reliability and the hypothesis used during the development of each physical model. Extrapolation to other boundary conditions using the DST method has not been investigated yet. Results presented, for instance, in [25-26] concern only long-term 
The literature survey carried shows that there is no reliable and generic method allowing RETS long-term energy performance prediction in different conditions. As described earlier, some of the current methods (component approach) are not able to model the real system behaviour and the real interactions between its components. The other methods (global approach) at present cannot be applied to evaluate different type of systems which make them not generic. Also, all of these methods should be applied by an expert due to their complexity, which is not helpful to be used as a certification tool. Various experts point out that the lack of performance guarantees is a serious impediment to the commercial development of these thermal system units [28].

The current work presents a new Solar Combisystem performance evaluation methodology. Indeed, the proposed method does not assume any prior knowledge about the system to be modelled or its components. This makes the method generic, more relevant for a future tool to evaluate RETS energy performance within the framework of a certification context and easy to use by nonexpert people. This methodology is based on a short dynamic test and the identification of a "black box" model of the system using ANN.

91 Following [29], the method can be rated as Whole system - Indoor laboratory - Controlled dynamic conditions - Behavioural model parameters - Simulation. By means of this technique, it will be possible to evaluate the performance that the tested system will have when installed in any working environment or boundary condition. As a consequence, comparing systems and establishing performance guarantees become possible.

The present study is focused on the category of RETS that provides both SH and SC as well as DHW from a common array of solar thermal collectors, backed up by an auxiliary non-solar heat source: a gas boiler, a heat pump or both. These systems are presented in section 2. In section 3 the proposed performance evaluation approach for SCSs is described, a literature summary of the application of ANN in system modelling is given as well. In section 4 results of the developed methodology are presented and discussed, while some perspectives and future studies are given in the conclusion part.

\section{SCS description}

101 The methodology should be generic. In order to ensure that it could be applied to different systems types, three different types of systems were considered during the validation process: i) the Solar Combisystem combined with an air source heat pump (SCSASHP), ii) the Solar Combisystem combined with a water source heat pump (SCSWSHP) and iii) Solar Combisystem combined with a gas boiler (SCSGB).

These systems are representative of those proposed by manufactures on the current market. Drawings of the three types are represented in Figures 2 and 3. The distinguishing features of each system are briefly described in Table 1. The condensing gas boiler can directly heat the water returning from the space heating emitter. It can simultaneously heat the storage tank and the space heating emitter. The heat pumps are connected to the store via three pipes. The highest of the connections is used for charging the volume nominally for DHW preparation while the middle one is designed to charge the volume for space heating buffering. Heat pumps can also directly heat the water returning from the space heating emitter. The solar collectors of all three systems charge the storage via an internal heat exchanger and the DHW is prepared with an internal heat exchanger covering the whole height of the store. 
Table. 1: The distinguishing features of the SCSs studied

\begin{tabular}{lllll}
\hline Auxiliary system & Nominal capacity $(\mathrm{kW})$ & Storage volume (l) & Compressor characteristics & System classification $^{\mathrm{a}}$ \\
\hline Air source HP & 8.24 & 750 & Variable speed & Parallel system \\
Water source HP & 8.24 & 750 & Fixed speed & Parallel system \\
Gas Boiler (GB) & 28 & 736 & -- & -- \\
\hline
\end{tabular}

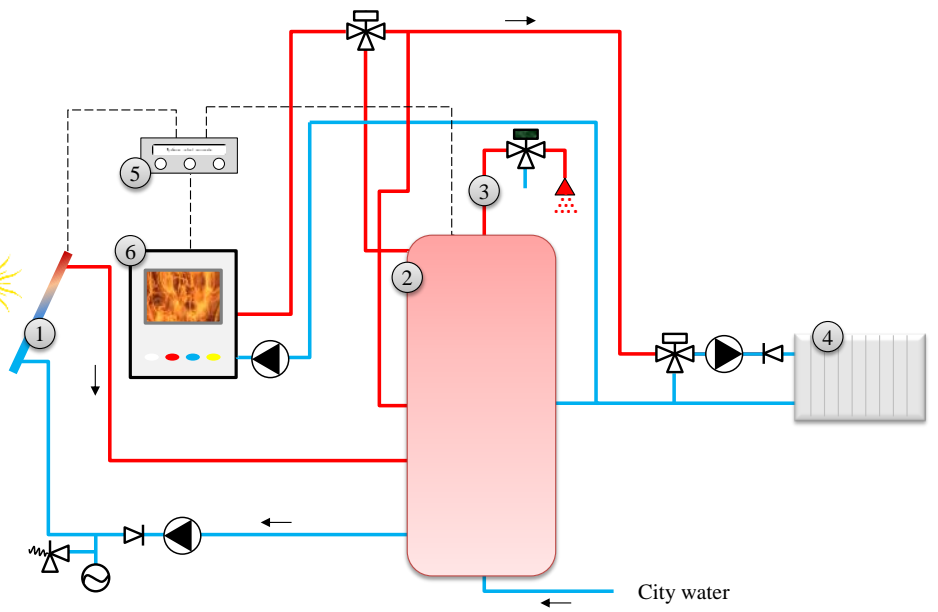

Figure. 2: Simplified hydraulic scheme of the SCSGB modelled in the present study and tested in the semi-virtual test bench. System components are: (1) collector, (2) tank storage, (3) DHW tap, (4) SH emitter, (5) control system and (6) gas boiler.

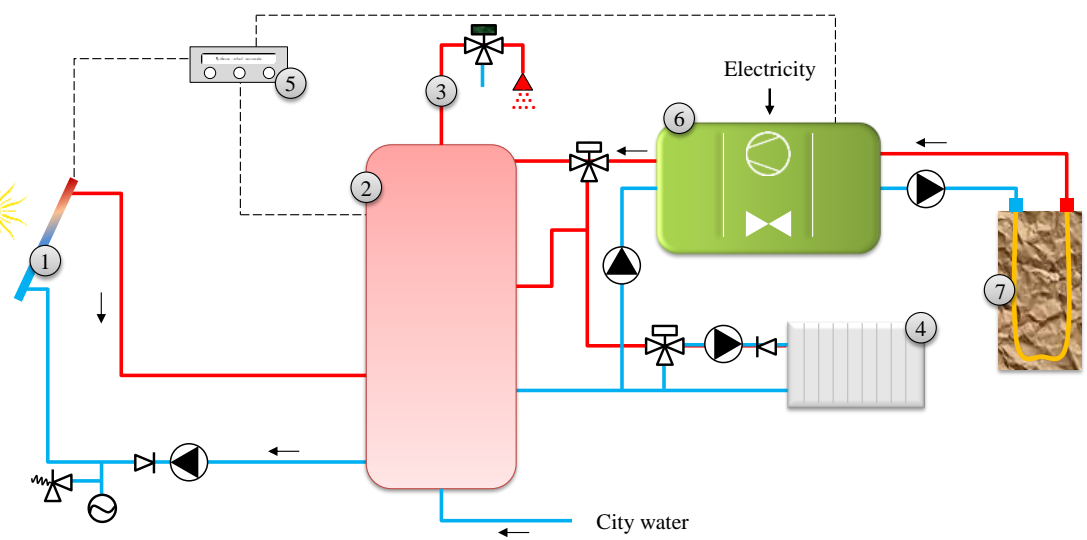

Figure. 3: Simplified hydraulic scheme of the SCSWSHP modelled in the present study. The system components are: : (1) collector, (2) tank storage, (3) DHW tap, (4) SH emitter, (5) control system (6) heat pump, (7) ground heat exchanger. The drawing of the SCSASHP can be deduced by changing the water source HP to an air source HP.

\section{Proposed performance evaluation approach for SCS}

To be relevant and overcome the weaknesses of the current methods, the modelling methodology must comply with the following

(i) It must be generic so it can be used with several SCSs for building applications: Combisystems with a heat pump or boiler auxiliary, absorption chiller, etc.

(ii) It must be nonintrusive so this method can be used to model a system using only its inputs and outputs. There is no need to 
(iii) The method must take into account the whole system so all interactions between subsystems are modelled. The real behaviour of the system will thus be modelled.

(iv) The system procedure test must be short so the cost of the qualification test is low.

(v) The method must allow predicting the system performance for several boundary conditions, different from the test conditions. This will enable characterization of the system's performance.

To fulfil the first, second and third requirements, the most appropriate solution consists in using a "black box" model. In contrast to a physical detailed model, designing a "black box" model does not require knowing the system's internal parameters such as the efficiency of its sub-systems, thermal conductivities and the mechanisms of the control and regulation systems. When using a "black box" model, modelling simplification hypotheses necessary to build a physical model, which usually leads to errors, are bypassed. Therefore, it is possible to identify a global model of the system without being intrusive. As presented in section 1, a global approach appears more relevant to fulfil the third and fourth requirements. The novel methodology proposed in this paper is based on the SCSPT that has been developed at INES, the French National Institute for Solar Energy. Artificial intelligence methods are able to learn from data, so an efficient model can be created with a good ability to generalize results to new data. ANNs, presented in section 3.3.1, fulfil the fifth condition.

The five steps to model and then to evaluate the performance of a system following the proposed approach are represented in Figure 4. The proposed methodology consists on first testing the system to be characterized in a semi-virtual test bench during a short sequence of time, typically 12 days, and in a dynamic way. Then the harvested data will serve to design a dynamic neural network model of the system. Basically, the ANN learns the internal behaviour of the tested system. The model will then be used to predict the system's behaviour, e.g. its annual energy consumption, when unseen data are presented to it and thus evaluate its performance.

\subsection{The Short Cycle System Performance Test (SCSPT)}

The SCSPT method is composed of two main stages: The determination of a relevant weather test sequence and the real system test on a semi-virtual test bench. In the following the semi-virtual test bench, the test sequence and boundary conditions are presented.

\subsubsection{The semi-virtual test bench}

The semi-virtual test bench was developed to test thermal systems by confronting them to a virtual environment. In fact, the whole system, including all of its components except the solar thermal collector and the geothermal heat exchanger (in the case of a SCSWSHP), is physically installed on the test bench, as is usual in a building. The collector and the geothermal heat exchanger are not included because it is very expensive to control climatic variables (Solar radiation, air velocity, soil temperature, etc.). To create reproducible boundary conditions, weather variables, collectors, geothermal heat exchanger, DHW draw-offs, the heat 
emitter and the building are simulated, in real time, within the TRNSYS software. The semi-virtual test bench is represented in Figure 5.

The solar collector model used is the one defined in [30]. Most particularly one can model flat plate and vacuum tube collectors. The parameters of the model are identified using standard tests. Moreover, the borehole model used is described in [31].

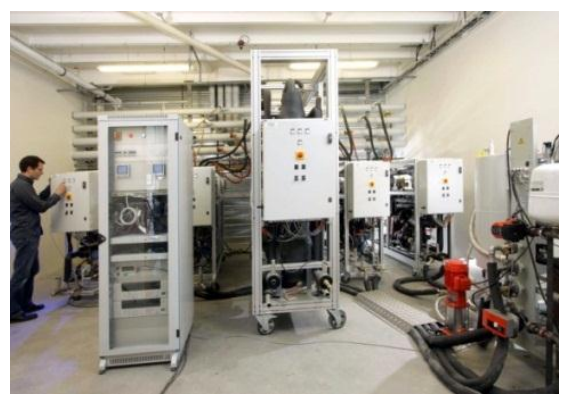

Figure. 5: The semi-virtual test bench located at INES, France

The real system and the virtual environment communicate via hydraulic modules. Modules are plugged into a hot water $\left(180{ }^{\circ} \mathrm{C}\right)$ and a cold water $\left(-10^{\circ} \mathrm{C}\right)$ network, supplied by a central heating and cooling system. Thus, by means of heat exchangers, each module can produce or consume heat quickly from a secondary fluid when so ordered. Each loop of the Combisystem (mainly DHW, SH, SC, collector and geothermal heat exchanger loops) is connected to a module. At every time step (1 min), modules record the temperature and the flow rate of incoming fluids and send these measurements to the monitoring computer. These measurements are used as inputs to the TRNSYS simulation software. Then, according to the outputs of the TRNSYS calculation, fluid temperatures at the outlet of the modules are adjusted. This way, each module emulates every virtual component simulated by the software.

\subsubsection{The test sequence and boundary conditions}

The test sequence is a series of 12 weather days selected and applied to the Solar Combisystem during the test. This sequence is determined by an algorithm [32] based on TRNSYS simulations of a reference Combisystem so that two criteria are fulfilled:

- The tested system uses proportionately the same auxiliary energy during the test sequence as it would use during a complete year with the same boundary conditions. As a result, the auxiliary energy annual consumption is evaluated by a simple extrapolation, which corresponds to a multiplication by a factor equal to $365 / 12$.

- $\quad$ Storage energy variations, SH and SC loads are equivalent, day by day during the sequence test to month by month during the annual sequence.

The boundary conditions are simulated by a building model defined in the IEA Solar Heating and Cooling program Task 32 [33], a standard DHW draw-off profile and a specific 12-day weather data sequence selected from the annual weather data using the algorithm presented above.

Boundary conditions for the systems considered in this study - temperatures (outdoor, ground), solar radiation, air velocity, humidity, loads etc. - are all determined by the collector area, the building quality and the climate where the system is installed. Therefore, in the present study, boundary conditions will be indicated as the climate-building-collector area. The reference buildings described in Task32 of the IEA SHC: SFH30, SFH60 and SFH100 (e.g. single family house (SFH) with space heating loads of $30 \mathrm{kWh} / \mathrm{m}^{2}, 60 \mathrm{kWh} / \mathrm{m}^{2}$ and $100 \mathrm{kWh} / \mathrm{m}^{2}$, respectively, over 1 year for the Zurich climate); Zurich, Stockholm and 
192 Barcelona climates are adopted herein. For instance, the boundary condition "Zurich SFH60 $10 \mathrm{~m}^{2}$ " means that the Solar

193 Combisystem is installed in an SFH60 building type in Zurich with a collector area covering $10 \mathrm{~m}^{2}$.

The global "black box" model identification of the system is the core of the methodology. The identification is made using the data gathered during the system test following the SCSPT procedure.

\subsubsection{Artificial neural networks}

198 ANNs seem to be the most powerful mathematic tool to solve this modelling problem. It has been shown that they are universal function approximators [34], so they can be used to approximate the system's function. ANNs have been applied successfully to solve complex, nonlinear, dynamic and multivariable problems. They tolerate errors, imprecisions and missing data [35]. ANNs have been used extensively during the last decade, most particularly to solve prediction and modelling problems in the renewable energy field. In the following, a brief summary of the most recent studies on modelling SCSs by ANNs is presented.

In [36] the author used ANNs to predict long-term performance of forced circulation-type solar domestic water heating. The monthly predictions of the model developed were highly satisfactory. In [37], an approach based on an ANN model to predict the performance of a direct expansion solar-assisted heat pump was developed. The training data were obtained from the experimentation at different solar intensities and ambient temperatures. Because the system does not integrate tank storage, which has a high thermal inertia, the static ANN model used was enough to obtain relevant results. In [38] the authors investigated the ability of a static ANN to model the energy behaviour of a typical large solar thermal system. From the results presented, it can be concluded that the ANN effectively predicts the daily energy output of the system knowing the daily total incident radiation at the collector level, the daytime average ambient temperature and the storage tank water temperature at the start of the day. The ANN results were also compared to predictions of another validated method with satisfactory agreements. In [39] the authors developed a tool for checking annual energy performance and certification of buildings using ANNs. Inputs of the model are composed of building geometric parameters, climate information and types of energy systems integrated into the building. The results of the neural model implemented show a good correlation with the actual data. In [40] the authors developed an ANN-based model of a solar-driven absorption chiller. The model developed was able to predict both the coefficient of performance and the system's cooling capacity with a low error. For this study, only five inputs were relevant to model the whole system, i.e. the inlet and outlet temperatures of the evaporator and generator, and the average temperature of the hot water storage tank. The inputs of the modelling configuration used are not suitable to evaluate the performance of an absorption chiller when only inlet temperatures and flow rates are available.

220 Several other ANN modelling studies have been reported recently, but they focused on modelling isolated system components [41], [42], [43], [44], [45], [46].

ANN theory is clearly presented in [47] and [48]. ANNs are parametric analytical functions whose concept takes inspiration from the human central nervous system. A neuron, the basic element of an ANN, can compute values $z_{l}$ from a weighted summation of its inputs $x_{j}$. The summation coefficients $\omega_{j}^{l}$ are called synaptic weights. The subscript $l$ denotes the neuron number. The neural operation is presented in eq. 1 . The function $f_{l}$ is called the neural activation function (AF).

$$
z_{l}=f_{l}\left(\sum_{j=1}^{K} \omega_{j}^{l} x_{j}\right) \text { eq. } 1
$$


class of the multi-layer perceptron (MLP). A MLP is a feed-forward network built of neurons, arranged in layers. It has an input layer, one or more hidden layers and an output layer. In Figure 6 a MLP, with $E$ inputs, $C$ neurons in the hidden layer and $S$ outputs, is presented. The $s^{\text {th }}$ output of the network can be obtained using eq. 2 .

$$
y_{s}=f_{s}^{S}\left(\sum_{c=1}^{C} \omega_{c, s}^{S} f_{c}^{C}\left(\sum_{e=1}^{E} \omega_{e, c}^{C} u_{e}\right)\right) \text { eq. } 2
$$

Modelling a system using an ANN means building the appropriate network architecture (hidden layers, neurons, AFs) and identifying the different weights.
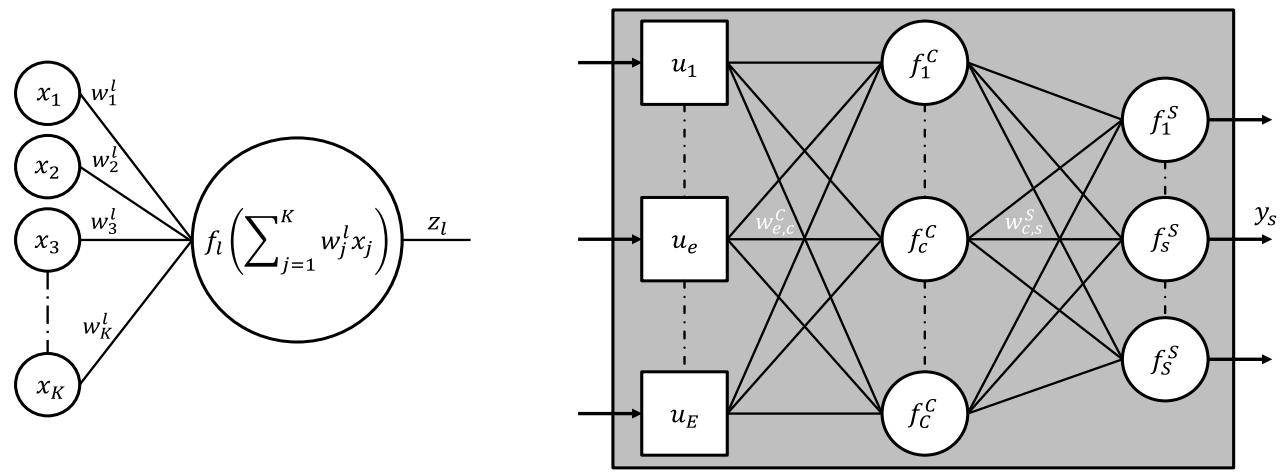

Figure. 6: Formal representation of a neuron (left), example of a neural network MLP with one hidden layer (right)

\subsubsection{Optimization algorithm}

This section considers models with one output. The multi-output case can be deduced from the simple case. The modelling problem is equivalent to the determination of an unknown real function $F: R^{E} \rightarrow R$ that defines the relation between inputs and the output of the system. When the identification of this function is based on an input-output $D_{N}=\{\boldsymbol{u}(t), y(t)\}_{t=1}^{N}$ set of experimental data, the modelling process is called "black box" modelling. In this case, the relation between inputs and output experimental data can be described as:

$$
y(t)=F(\boldsymbol{u}(t))+e(t) \text { eq. } 3
$$

where $e$ is the observation noise and $\boldsymbol{u}$ is a vector that contains all the system inputs. The noise is usually assumed to have a normal distribution with a zero mean. The system model is an approximation of this relation but uses a parametric function $\hat{F}$ :

$$
\hat{y}(t)=\hat{F}(\boldsymbol{\varphi}(t) ; \boldsymbol{w}) \text { eq. } 4
$$

where $\boldsymbol{\varphi}$, called the model regressor, is a vector formed by the chosen model inputs, at different times, and only the chosen delayed outputs.

The model implements a $R^{I} \rightarrow R$ mapping as well; $\hat{y}$ is the output of the model and $\boldsymbol{w}$ is a vector of parameters to be determined (synaptic weights). In this study, the structure of the system model is an ANN. The determination process of all elements and parameters of the ANN such that it fits the observations is called the learning or training process. Parameters are always estimated used is the mean square error (MSE): 
Under the assumptions presented in this section, the solution of the problem can be expressed as:

$$
\widehat{\boldsymbol{w}}=\arg \min _{\boldsymbol{w}} \operatorname{Obj}\left(\boldsymbol{w} ; D_{N}\right) \text { eq. } 6
$$

There exist two categories of methods to find this minimum: the gradient-free and the gradient-based methods. Gradient-free methods are able to approximate the minimum without calculating the gradient. They use only the values of the objective function. Genetic algorithms and the simplex method are two examples in this category. Gradient-based methods are based on direct or indirect derivative calculation of the objective function. The Levenberg-Marquardt (LM) [49] method belongs to the second category. LM is a kind of combination between the Newton method and the gradient descent. This method was designed to overcome the calculation of the Hessian matrix, which is very expensive to calculate. The LM algorithm uses an approximation $\widetilde{H}$ to the Hessian matrix in the following Newton-like update:

$$
\boldsymbol{w}^{(i+1)}=\boldsymbol{w}^{(i)}-\left[\widetilde{H}\left(\boldsymbol{w}^{(i)}\right)+\mu^{(i)} I\right]^{-1} G\left(\boldsymbol{w}^{(i)}\right) \quad \text { eq. } 7
$$

Note that the initial step size must be indicated by the user. When the scalar $\mu^{(i)}$ is zero, this is simply the Newton method, using the approximate Hessian matrix. When $\mu^{(i)}$ is large, this becomes a gradient descent with a small step size. The Newton method is faster and more accurate near an error minimum, so the aim is to shift toward the Newton method as quickly as possible. The authors found in [50] that the LM algorithm is more relevant than the other optimization algorithms that were tested (gradient descent with momentum, scaled conjugate gradient, resilient back propagation). This is why it was adopted for the methodology developed herein.

\subsubsection{Training strategy}

As explained in section 3.3.2, the goal of optimization algorithms is to determine the ANN weights that minimize the model error based on the training data (observations). Usually, the resulting models fit the learning data set with high accuracy. However, the model prediction precision may be very poor for unseen data. In some cases, this means that the resulting model has learnt only characteristics of the training data set and not the system's behaviour. In other cases, probably the optimizer has been stacked in a local minimum. The learning strategies are ways to deal with those optimization algorithms and the ANN structure in order to obtain a model that has good generalization ability. One must be aware that all the optimization algorithms based on the gradient are local methods. In fact, they are, generally, valid only for a region near the minimum. This is why a good way to prevent the algorithms to be stacked on a local poor minimum is to train the ANN several times with different starting points (weights initialization). The initialization method used in the proposed methodology is the Nguyen-Widrow method [51]. present work, the short time of the system test, 12 days, restricts the amount of data available for training. Therefore, mathematicians had to develop a learning algorithm that can use a restricted data set without compromising the model's generalization ability. For this reason, it is relevant to use a regularization method for the learning process. Typically, training aims to reduce the sum of squared errors. Regularization modifies the objective function by adding an additional term: the sum of squares of the network weights to the objective function, which becomes:

$$
\operatorname{Obj}\left(\boldsymbol{w} ; D_{N}\right)=\alpha \operatorname{MSE}\left(\boldsymbol{w} ; D_{N}\right)+\beta \boldsymbol{w}^{T} \boldsymbol{w} \text { eq. } 8
$$
weights, the training process produces an ANN with good generalization ability [52]. In fact, by keeping the weights small, the model response will be smooth and so over-fitting is assumed to be prevented. 
The definition of the modelling input-output configuration is crucial to develop a generic methodology. Generally, SCS physical inputs and outputs differ from one to another. They depend on the energy sources used by the system and how this was designed by the manufacturer. However, energy systems can be represented in terms of power transformation between the renewable energy source, the load and auxiliary system. This is why a compact configuration with three inputs $-P_{d h w}$ (DHW energy rate demand), $A . G$ (solar irradiation on the collector plane), $P_{s h}$ (SH energy rate demand) and one output $P_{\text {aux }}$ (auxiliary system energy rate) - was selected. This open configuration, not particular to a specific system, is relevant to develop a global method. In a recent study of the authors [53], the results concerning Solar Combisystem modelling showed that a nonlinear auto-regressive ANN model with exogenous inputs (NARX), for which the regressor is similar to eq. 9, is more efficient than a static model. The latter does not learn the dynamics of the system, most particularly because of heat storage component inertia. For this reason, a dynamic neural network was used.

$$
\boldsymbol{\varphi}(t)=[\boldsymbol{u}(t), \boldsymbol{u}(t-1), \ldots, \boldsymbol{u}(t-M), y(t-1), y(t-2), \ldots, y(t-P)] \text { eq. } 9
$$

$M$ and $P$ define the modelling lag space.

When using a dynamic model, the question of how many delayed inputs and outputs to choose arises. There is no rule to find the right time delays that are necessary to model a system because it depends a great deal on the data and the model structure. In the present work, time delays are chosen following a trial and error process. Some methods found in the literature (for instance [54]) were tested but they did not give satisfactory results.

\subsubsection{Data preparation for training}

Usually, training algorithms (even if coupled to an adequate training strategy) do not necessarily guarantee the production of efficient networks based on raw data. This is why it is essential to carry out some data pre-processing before training. By normalizing or standardizing the input and target data vectors, the ANN training will be easier and faster, and all vectors will be equally taken into account during the learning process. As a consequence all vectors are equally important. Equation 10 will be used to pre-treat the training data in order to fall between nor $_{\min }$ and nor ${ }_{\max }$ (normalization bounds); $x$ represents a vector (input or output of the model) of data over time. data set. data. To smooth the collected data, a moving average of five time steps was applied to them.

The activation functions chosen to be used in the methodology are, in the hidden layer, the tangent hyperbolic function tanh and, in the output layer, tanh or a linear function $(f: x \rightarrow x)$. As mentioned in section 3.3.1, and if tanh is considered rather than the linear function in the output layer, the model's structure has only one output $\left(\hat{P}_{\text {aux }}\right)$, which is given by:

$$
y_{s}=\tanh \left(\sum_{c=1}^{C} \omega_{c, S}^{S} \tanh \left(\sum_{e=1}^{E} \omega_{e, c}^{C} u_{e}\right)\right) \text { eq. } 11
$$




$$
y_{s}=\tanh \left(b_{s}^{S}+\sum_{c=1}^{C} \omega_{c, S}^{S} \tanh \left(b_{c}^{C}+\sum_{e=1}^{E} \omega_{e, c}^{C} u_{e}\right)\right) \text { eq. } 12
$$

where $b_{c}^{C}$ and $b_{s}^{S}$ are synaptic weights of the bias to the hidden and output layers, respectively.

329 Following eqs. 10 and 12, with tanh bounded between -1 and 1 , and by applying triangle inequality, the following can be deduced:

$$
\psi<\hat{P}_{a u x}<\vartheta \text { eq. } 13
$$

where:

From eq. 13 it appears that the output from the network is bounded. In order to enhance the extrapolation ability of the ANNs, the normalization bounds were chosen carefully so that the bounds in eq. 13 would be large enough. In the case of a linear function, the normalization bounds are flexible. This is why a fixed normalization interval of \pm 1 is used for all models. should reflect the nonlinear and dynamic behaviour of the system to be evaluated as much as possible. The authors have specific days from the days of the year in three climates (Zurich, Stockholm and Barcelona). The goal was to create a learning satisfactory results obtained to date. Therefore, the latter was retained to create training data.

345 Proposals for the optimal number of neurons to be used in the hidden layer can be found in the literature. Some of them give this number as a function of the size of the training data set and input-output numbers [55]. Other methods try to give the maximum number of neurons that is accepted and do not compromise the generalization ability of the network [56]. None of these methods has been proved and it is easy to find a counter example for each one [57]. The method retained herein is intended to fix a between 1 and $H_{\max }$ will be selected.

$$
B I C=\ln M S E+q \frac{\ln N}{N} \text { eq. } 16
$$


The MSE (see eq. 5) in BIC is calculated using the training data and in a closed loop architecture (see Figure 7), in which inputs and the initial values of the outputs, are used to predict the outputs (long-term model simulation) at future time steps.

357 Because the true output is available during the training of the network it is efficient to use it instead of feeding back the estimated 358 output. The resulting architecture is called open loop architecture (see Figure 7). The advantage of this architecture (used only 359 during training) is that the input to the ANN is more accurate.

360 The BIC selects ANNs, that have a lower BIC value, with a small number of parameters (synaptic weights). This is advantageous 361 because ANNs with a reduced number of parameters have a better generalization power as stated in [59].

362 The whole training and selection process was developed in MATLAB R2012b and is represented in Figure 8. This process was 363 repeated for each model structure when changing time delays, normalization bounds and the output AF.
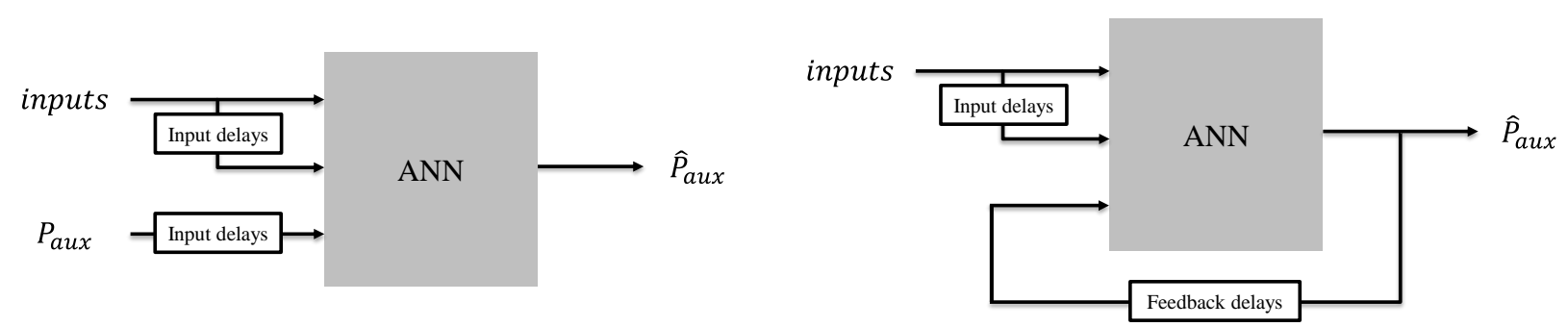

Figure. 7: Open loop architecture (left) and closed loop architecture (right)

366 In the following section, the results of two different models for each system are presented:

- ANN1 is the model that is selected as the best model after the comparison of its performance with all the created ANNs 


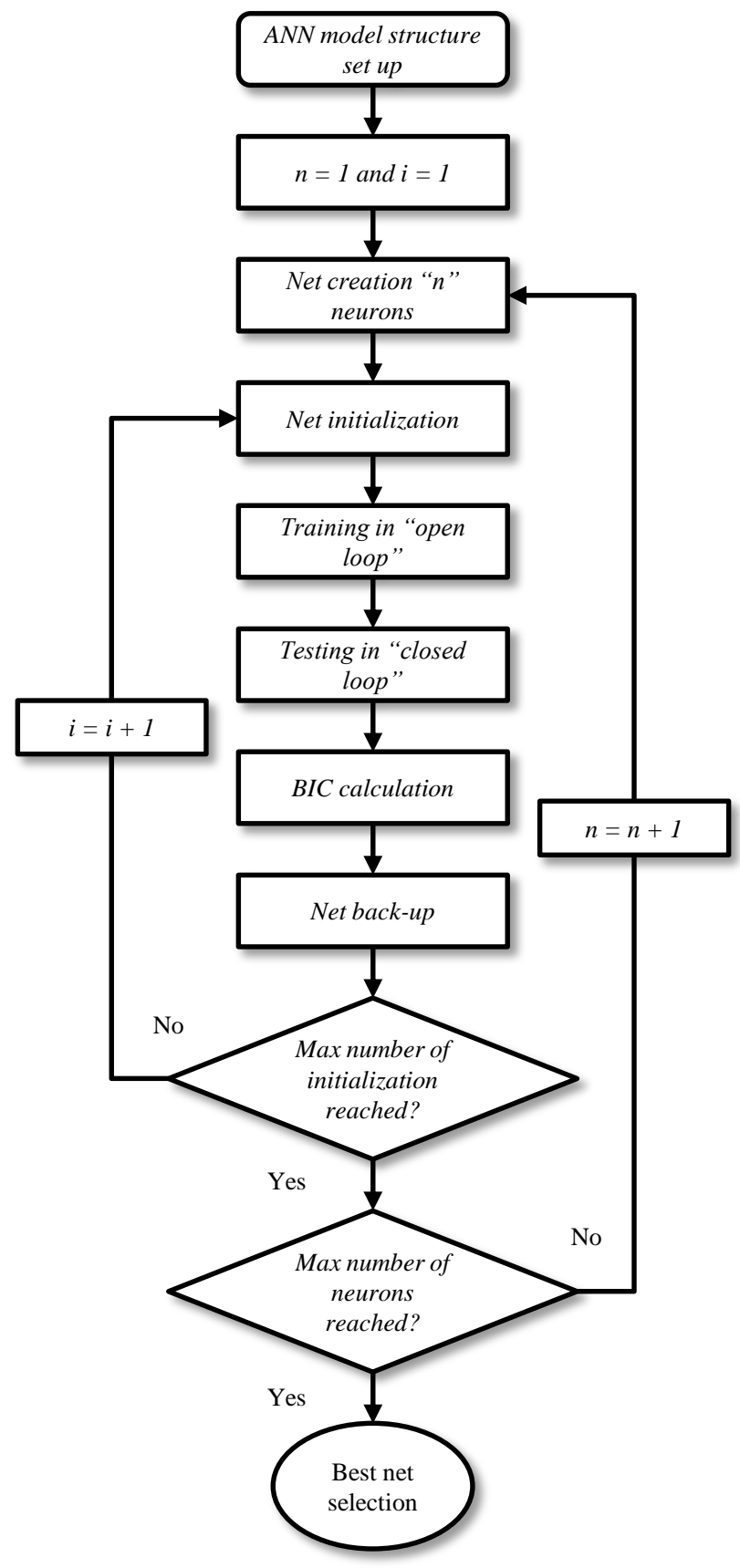

Figure. 8: The training process algorithm applied to each model structure

\section{4. Results and discussion}

\section{4.1. Numerical validation}

374 This section presents the numerical results of the methodology application developed to evaluate the annual energy consumption

375 of four different SCSs. The used annual energy consumptions for model validation are simulated and not measured.

376 Testing all the systems physically over 1 year in different conditions is clearly impossible, so physical detailed and validated

377 TRNSYS models were used, instead of real systems, in order to validate the ANN predictions in the first step. 

the two SCSGB systems is represented in Figure 9 where the real system test will serve to create training data but annual simulations will be done using the TRNSYS model.

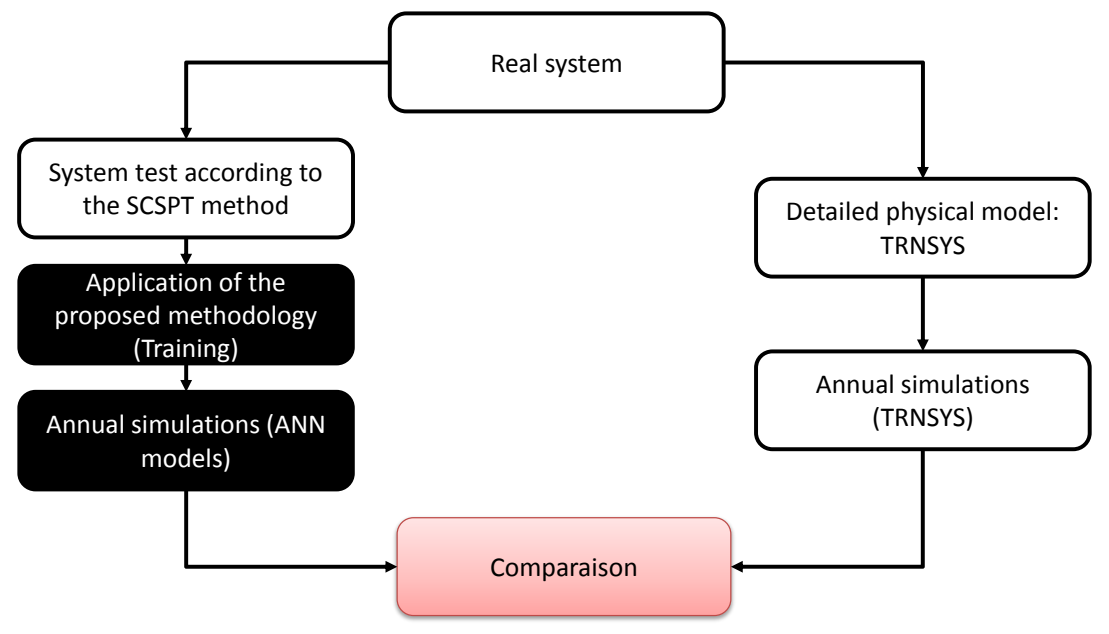

Figure. 9: Validation protocol based on the detailed TRNSYS model. It is used for the two SCSGB systems

\subsubsection{Description of systems models}

Four physical detailed models were selected to validate the methodology. All models were developed in TRNSYS software and some of them as part of the European MACSHEEP project [60]. The parameters of the main components were identified using experimental tests. In the following a brief description of each model is given:

- Standard SCSGB is a commercial SCS with a condensing gas boiler. The hydraulic scheme of this system is represented in Figure 2. This model does not take into account heat losses in the loops.

- Optimized SCSGB is a second system that was derived from the standard one. There is no physical difference between the two systems, but the control algorithm of the second one was optimized to improve the performance of the system.

- SCSWSHP and SCSASHP are two SCSs combined with a water or air source HP. The two systems are represented and described in section 2 .

For all systems, the target indoor and DHW temperatures are $20^{\circ} \mathrm{C}$ and $45^{\circ} \mathrm{C}$, respectively. The auxiliary systems are controlled to keep the upper part of the storage tank temperature near $50^{\circ} \mathrm{C}$.

According to the methodology, the systems to be evaluated must be physically tested to build the training data. To do so, the real systems corresponding to the Standard and Optimized SCSGB were tested according to the SCSPT method in the "Zurich SFH60 $16 \mathrm{~m}^{2}$ " boundary conditions, the conditions used for training. The real SCSs combined with HP were not available; their physical tests were simulated (in order to create the training data) using the detailed TRNSYS models in the same conditions as the two first systems (see Figure 10). Annual simulations using TRNSYS were done as well in order to compare them to those of the ANNs. 


\section{Detailed physical model:}

TRNSYS

401

402

403

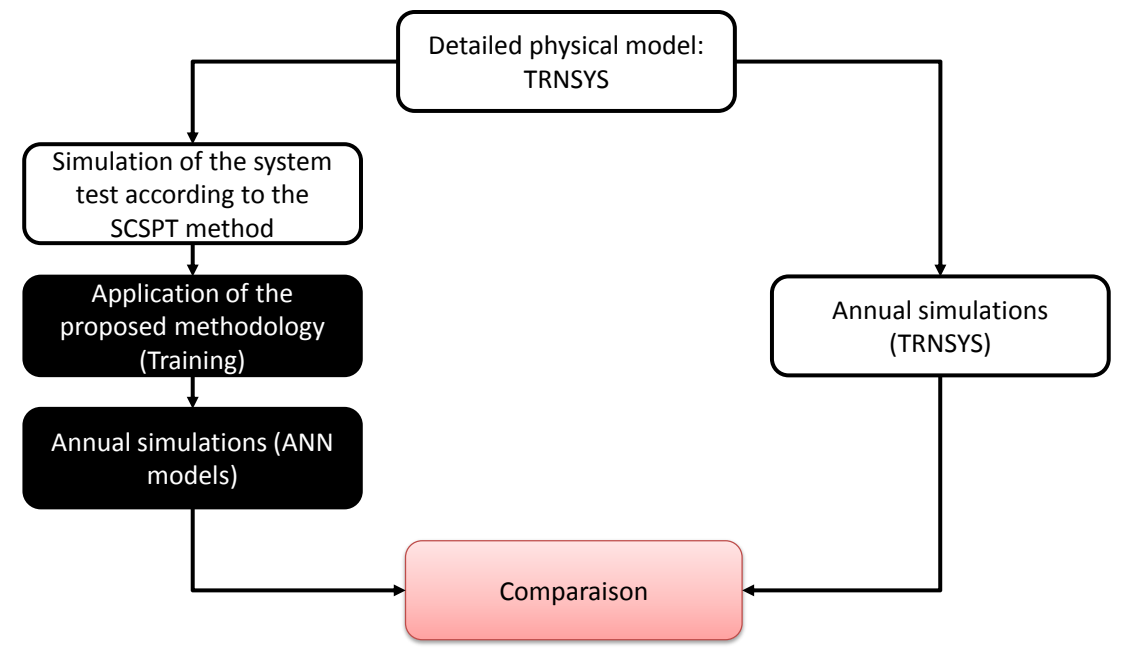

Figure. 10: Validation protocol based on the detailed TRNSYS model, used for the SCSASHP and SCSWSHP systems

\subsubsection{System energy consumption predictions}

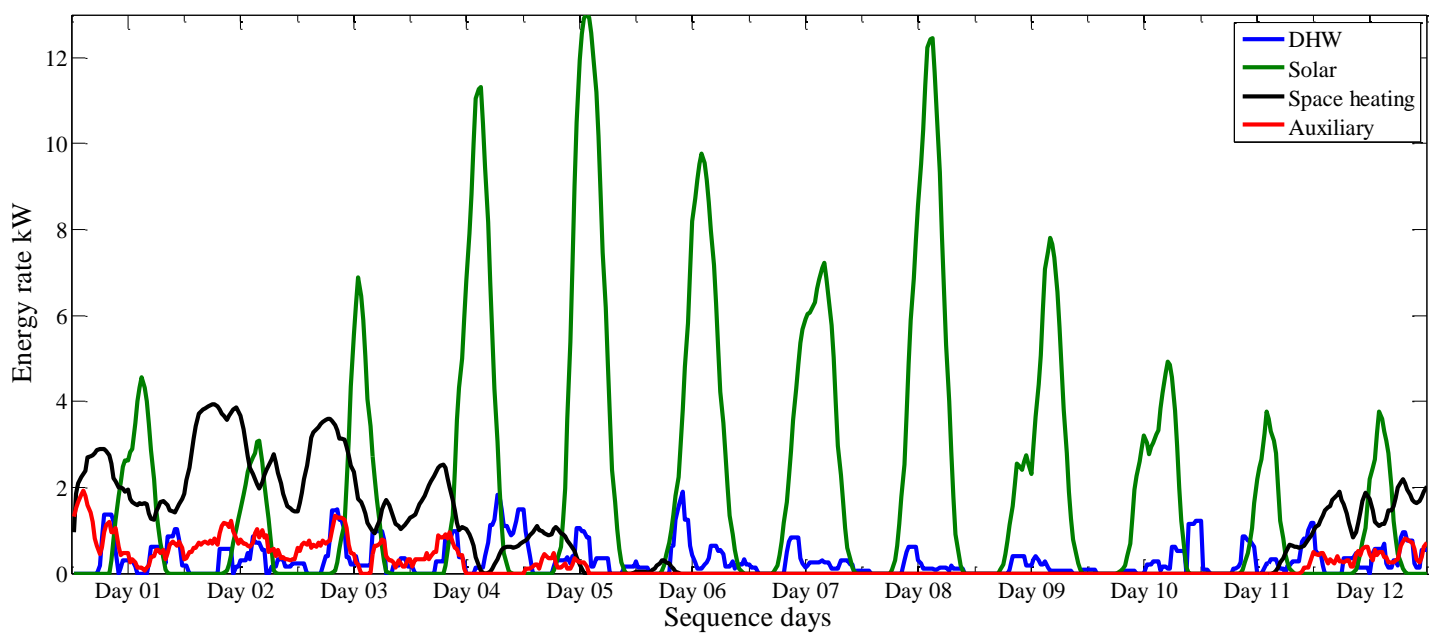

Figure. 11: Inputs (DHW energy rate, Solar irradiation and Space heating demand) and output (Energy rate of the auxiliary system, in this case the Heat Pump) training data, SCSWSHP, "Zurich SFH60 $16 \mathrm{~m}^{2}$ ". The data come from the simulated CSPT method.

The input-output data harvested during the tests were used to design dynamic ANN models for each system, according to the method described in section 3. An example of the data used for training is represented in Figure 11. The 12 days of the test sequence were applied successively without interruption. The features of the selected ANN models of each system are presented in Table 2.

All the neural models were used to make annual simulations in different boundary conditions (using the closed loop architecture). The annual prediction results of each ANN model are compared to those of the detailed TRNSYS models that represent here the reference. 
Table. 2: The distinguishing features of ANN modelling the four systems or physical models

\begin{tabular}{lllllll}
\hline Systems & Models & Normalization range & No. of neurons & Output AF & No. of feedback delays & No. of input delays \\
\hline \multirow{2}{*}{ Standard SCSGB } & ANN1 & \pm 0.4 & 5 & tanh & 1 & 0 \\
& ANN2 & \pm 0.4 & 5 & tanh & 1 & 0 \\
\multirow{3}{*}{ Optimized SCSGB } & ANN1 & \pm 1.0 & 2 & linear & 2 & 1 \\
& ANN2 & \pm 0.4 & 4 & tanh & 1 & 0 \\
SCSWSHP & ANN1 & \pm 1.0 & 2 & linear & 1 & 0 \\
\multirow{3}{*}{ SCSASHP } & ANN2 & \pm 1.0 & 13 & linear & 1 & 0 \\
& ANN1 & \pm 1.0 & 9 & linear & 1 & 0 \\
& ANN2 & \pm 0.2 & 7 & tanh & 2 & 1 \\
\hline
\end{tabular}

415 The most valuable criterion to evaluate the performance of a solar thermal system is to measure its energy consumption during a specific period of time. For this reason, the power consumed by the auxiliary system, output of the models, was integrated in time to predict the annual energy consumption of the systems per area of the building (each SFH has two floors measuring $70 \mathrm{~m}^{2}$ ). The estimation results are represented in Figures 12, 13, 14 and 15. Only one collector area $\left(19 \mathrm{~m}^{2}\right)$ different from the collector area used during training $\left(16 \mathrm{~m}^{2}\right)$ was considered to validate the ANN models. Varying this parameter in a wide range will not be meaningful because this parameter was not taken into account during the training process. In fact, during the system test (or its simulation) the collector area was fixed $\left(16 \mathrm{~m}^{2}\right)$.

Table. 3: Deviation in percent between the neural models and the reference for each boundary condition, case of the two SCSGB that were tested

\begin{tabular}{|c|c|c|c|c|c|c|c|c|c|}
\hline & & Zurich & Zurich & Stockholm & Stockholm & Stockholm & Stockholm & Barcelona & Barcelona \\
\hline & & SFH60 & SFH60 & SFH60 & SFH60 & SFH100 & SFH100 & SFH100 & SFH100 \\
\hline & & $16 \mathrm{~m}^{2}$ & $19 \mathrm{~m}^{2}$ & $16 \mathrm{~m}^{2}$ & $19 m^{2}$ & $16 \mathrm{~m}^{2}$ & $19 m^{2}$ & $16 \mathrm{~m}^{2}$ & $19 m^{2}$ \\
\hline Standard & ANN1 & $-2,07$ & $-2,10$ & $-9,09$ & $-9,61$ & $-7,52$ & $-7,95$ & 24,13 & 26,05 \\
\hline SCSGB & ANN2 & 6,87 & 4,90 & 0,61 & $-0,72$ & 5,17 & 4,44 & 42,37 & 41,20 \\
\hline Optimized & ANN1 & 2,53 & 0,11 & $-2,64$ & $-4,53$ & 9,98 & 8,21 & 42,09 & 37,12 \\
\hline SCSGB & ANN2 & 6,50 & 0,63 & 7,12 & 6,01 & 25,33 & 24,10 & 38,77 & 32,91 \\
\hline
\end{tabular}

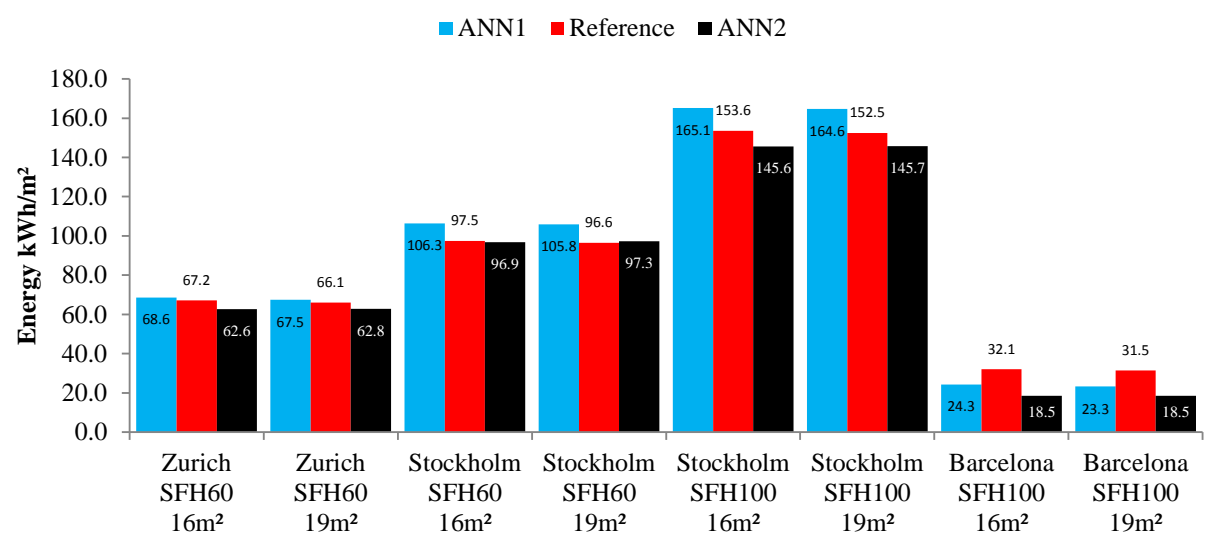




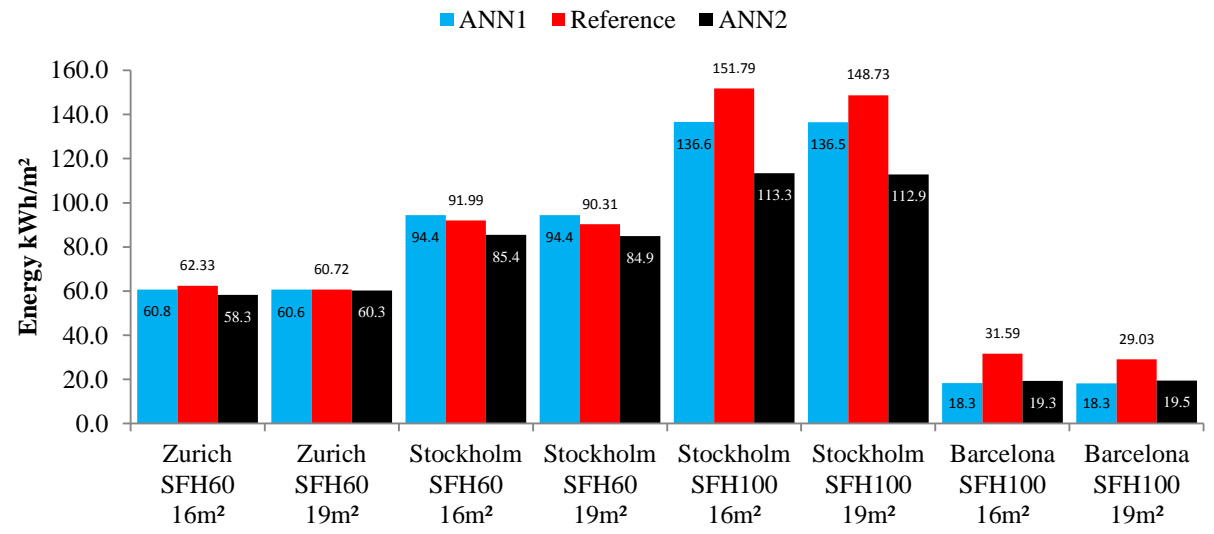

427 Each bar in the graphs represents the annual energy consumption per square metre of each system, estimated or calculated by the 428 corresponding model in one specific environment (boundary conditions): two with ANN and one using the reference model.

429 Table. 4: Deviation in percent between the neural models and the reference for each boundary condition, case of the two SCS combined to HP

\begin{tabular}{|c|c|c|c|c|c|c|c|c|c|}
\hline & & Zurich & Zurich & Stockholm & Stockholm & Stockholm & Stockholm & Barcelona & Barcelona \\
\hline & & SFH60 & SFH60 & SFH60 & SFH60 & SFH100 & SFH100 & SFH100 & SFH100 \\
\hline & & $16 \mathrm{~m}^{2}$ & $19 \mathrm{~m}^{2}$ & $16 \mathrm{~m}^{2}$ & $19 \mathrm{~m}^{2}$ & $16 \mathrm{~m}^{2}$ & $19 \mathrm{~m}^{2}$ & $16 \mathrm{~m}^{2}$ & $19 \mathrm{~m}^{2}$ \\
\hline Standard & ANN1 & 4,28 & 2,72 & 1,97 & 1,53 & $-2,70$ & $-3,84$ & $-30,19$ & $-36,85$ \\
\hline SCSWSHP & ANN2 & $-14,40$ & $-20,26$ & $-8,41$ & $-13,00$ & $-2,34$ & $-4,54$ & $-55,76$ & $-79,23$ \\
\hline Optimized & ANN1 & 18,84 & 15,95 & 12,44 & 14,91 & 14,64 & 14,11 & $-30,89$ & $-53,39$ \\
\hline SCSASHP & ANN2 & 34,49 & 33,79 & 35,63 & 35,79 & 42,99 & 43,46 & 17,99 & 14,13 \\
\hline
\end{tabular}

430 On the whole, the predictions of the "black box" models and the detailed TRNSYS simulations are very close. In fact, the 431 differences between the two methods in estimating system energy consumption are nearly within the $\pm 10 \%$ range for most 432 conditions, especially in the case of the SCS combined with water source HP.

433 For low heat demand boundary conditions (e.g. an environment with the Barcelona climate), the absolute differences are not 434 excessive but the low energy level makes these differences (deviation in percent) proportionally higher.

$\square \mathrm{ANN} 1 \quad$ Reference $\square \mathrm{ANN} 2$

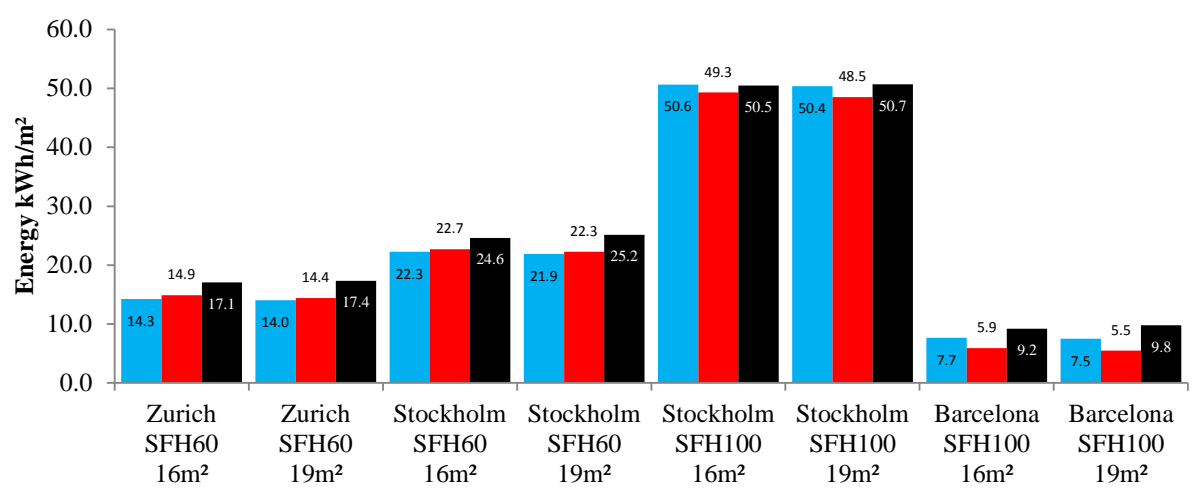

Figure. 14: Comparison of the ANN predictions and the TRNSYS calculations for annual energy consumption, SCSWSHP. 


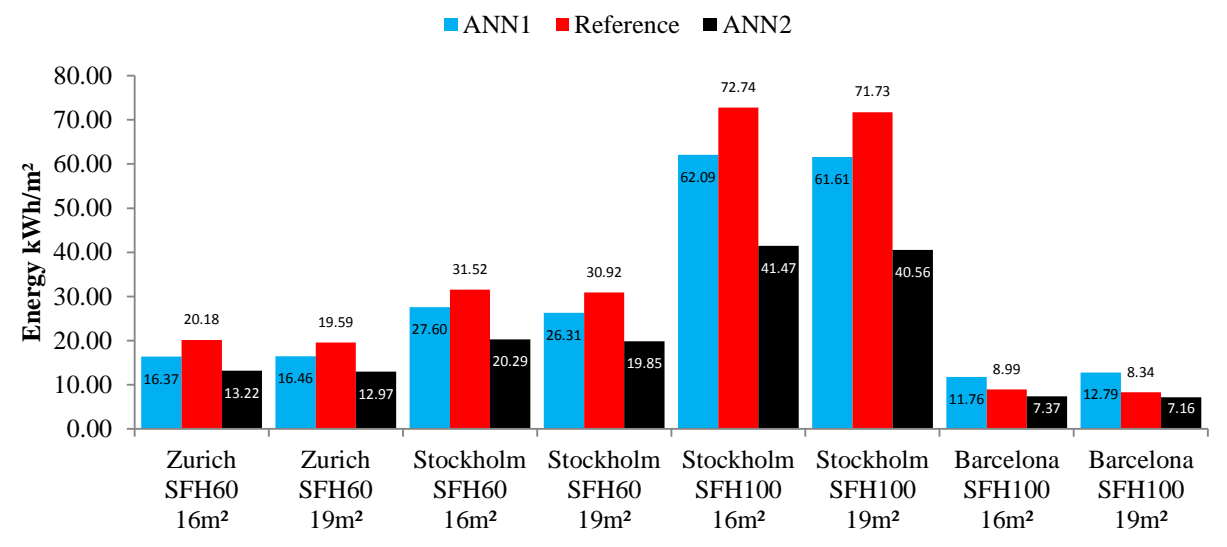

Figure. 15: Comparison of the ANN predictions and the TRNSYS calculations for annual energy consumption, SCSASHP.

The results show that the ANN model selection based on the BIC criterion does not select the best model. Several statistical criteria were used as well, but the results are not presented herein. Through the SCS modelling problem, the study shows that the commonly used model selection criteria are not able to identify the best neural network model for a wide range of unseen data prediction. This is in accordance with what is stated in [58]. However, the selected ANN models give acceptable precision estimates for all systems, but only for certain specific conditions close to the training conditions. In fact, according to Table 3 and 4, the deviations in percent for the Barcelona climate are the highest except for the SCSASHP system. Solar irradiation in Barcelona is higher all over the year compared to Zurich, the climate used for training. The two climates are so very different from each other.

The other neural models (ANN1) show very good results for all systems and could be very effective to predict systems' consumption for different conditions based only on a short dynamic test. Its error predictions for conditions that correspond to the Zurich climate are all less than 5\% except for the SCS combined with air source HP. The performance of the air source HP depends substantially on the outdoor temperatures. The days selected during the test sequence do not integrate a sufficient temperature distribution. This means that the learning sequence does not contain enough information about the system's characteristics. A solution would be to develop a dynamic learning sequence that represents all the system's working conditions.

Some environments are not realistic, e.g. they do not respect the design rules of Solar Combisystems such as combining a high solar collector area with a low heat-demand building. For those types of environments, predictions are less accurate but still acceptable because, as noticed above, the corresponding absolute differences are low (less than $4.3 \mathrm{kWh} / \mathrm{m}^{2}$ for the SCS combined to HP and less than $13 \mathrm{kWh} / \mathrm{m}^{2}$ for the SCS combined to a gas boiler). In general, neural networks do not work effectively in extrapolation mode. This means that if a set of data is very different from the one used during the learning process, the ANN predictions will be less accurate. It is commonly known that ANN estimation abilities stay good as long as means and variances of its inputs have values close to those used during training. In the present study, the results show that by manipulating the normalization bounds, it is possible to extend the ANN extrapolation capabilities. Indeed, Figure 11 shows that the training data corresponding to the energy rate of the auxiliary varies between $0 \mathrm{~kW}$ and $1.93 \mathrm{~kW}$. The same variable corresponding to the "Stockholm SFH100 $16 \mathrm{~m}^{2}$ " test conditions varies between $0 \mathrm{~kW}$ and $2.9 \mathrm{~kW}$ (Figure 16). This means that the neural models should predict a variable that is excessively out of range compared to the training data. However, Figure 16 shows that the ANN model was able to predict the output with a satisfactory accuracy especially in January and February (where the ANN is working in extrapolation). In fact, the coefficient of determination $\left(\mathrm{R}^{2}\right)$ is equal to 0.93 . 


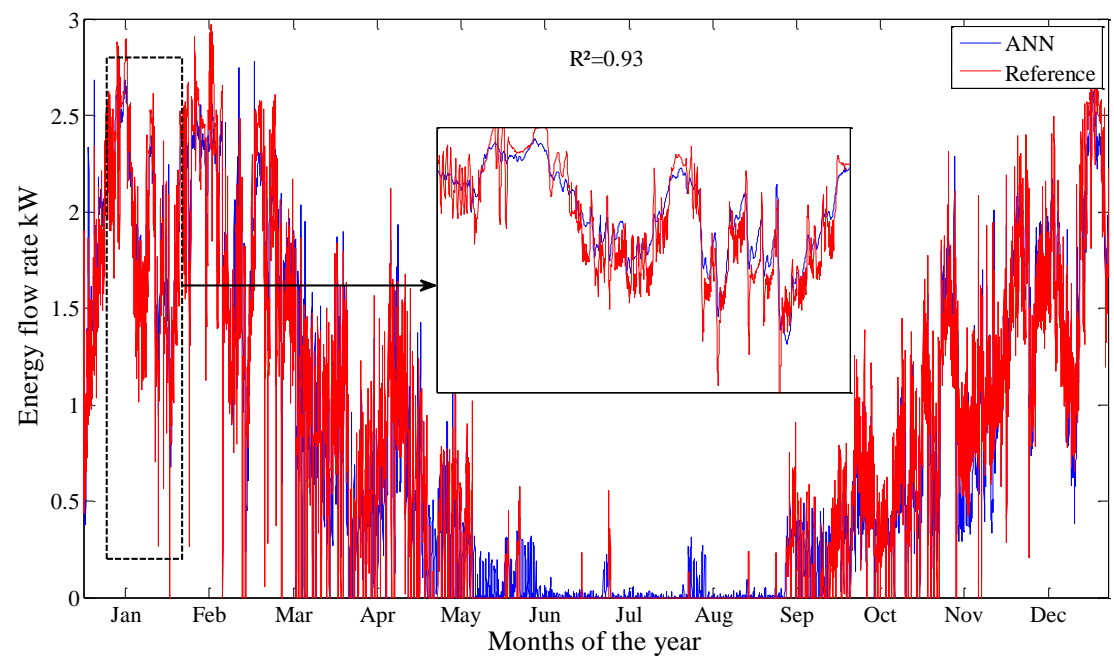

468 Figure 16 also shows that the neural network model is capable of predicting, with a satisfactory degree of accuracy (coefficient of determination $\mathrm{R}^{2}$ around 0.93 in "Stockholm SFH100 $16 \mathrm{~m}^{2 "}$ "), not only the annual energy, but also its rate.

\subsection{Experimental validation}

471 This section presents the results of the experimental validation of the methodology. For the SCS combined with a gas boiler, 472 predictions of the previous neural models developed in section 4.1.2 are compared to the test data but in a different condition 473 (Zurich SFH100 16m²). The two system tests are of 12 days (also according to the SCSPT method). The corresponding validation 474 protocol is represented in Figure 17.

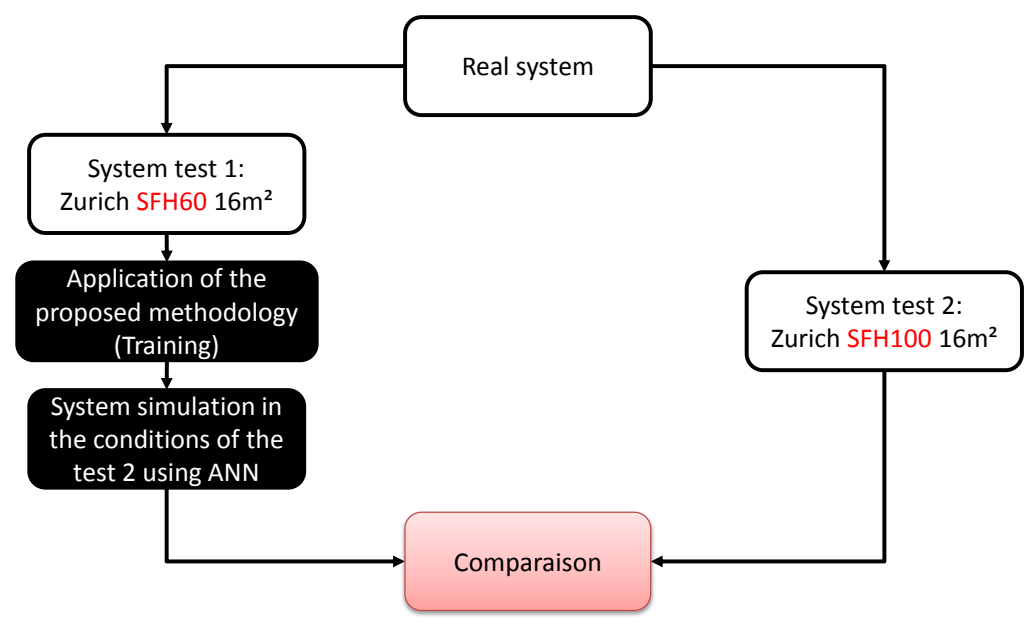

477 Concerning the system combined with HP, only the one combined with the water source HP was tested. Its model, developed on 478 the basis of the experimental data, was used to predict the annual system consumption in different conditions. This is equivalent to 479 a real application of the methodology.

481 The first two systems were presented in section 4.1.1. 
The SCS combined with water HP that was tested has the same hydraulic scheme as the system described and modelled in section 4.1, except that the thermodynamic valve upstream of the HP was replaced with two hydraulic pumps. The storage tank has the same volume as presented above and the HP has a lower nominal capacity of $8 \mathrm{~kW}$ compared to the system modelled in section 4.1. The application of the methodology in this case serves to show how it could be used in real life. In this example results are so not compared to any reference or measured data.

\subsubsection{Real neural model exploitation}

488 ANN models trained on the basis of the "Zurich SFH60 $16 \mathrm{~m}^{2}$ " test sequence in the Standard and Optimized SCSGB, presented in 489 section 4.1.1, were used to predict the systems' consumption over 12 days during another experimental sequence (“Zurich 490 SFH100 16 m²", see Figure 17). Figures 18 and 19 present the energy consumption prediction results.

491 The models selected based on the statistical criterion show very good results compared to the ANN1 model, especially for the 492 Optimized SCSGB. The difference between what the selected neural models predict and what is recorded during the test is less 493 than $0.3 \mathrm{kWh} / \mathrm{m}^{2}$.

Table. 5: Deviation in percent between the neural models and the measured data, case of the two SCSGB that were tested

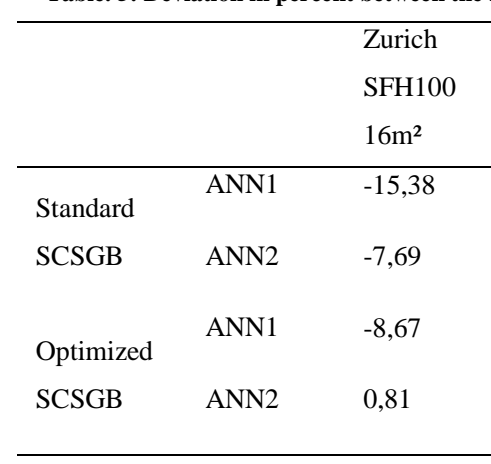

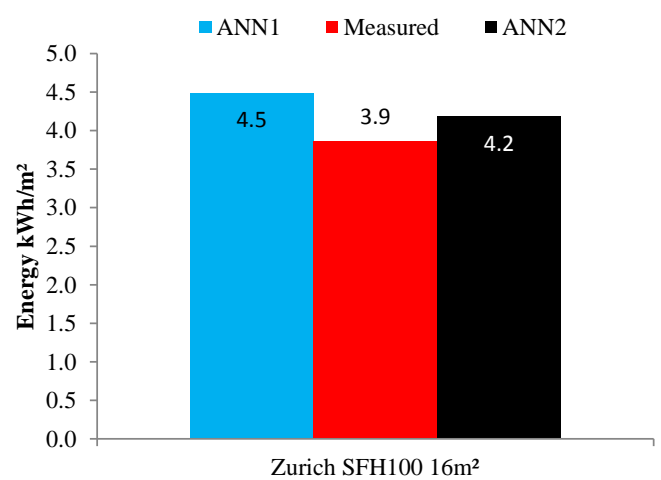




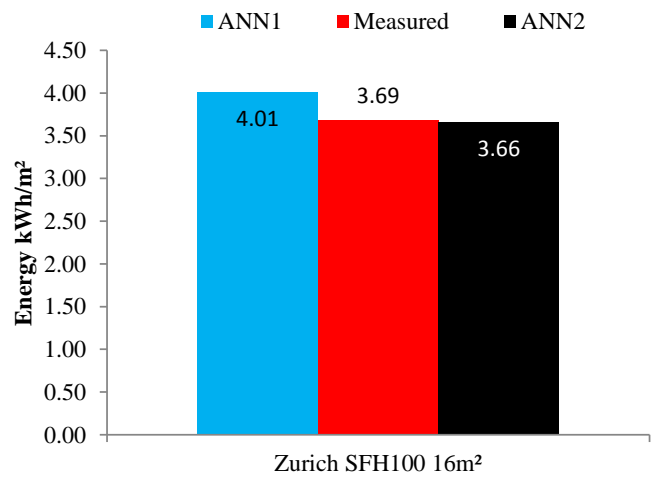

Figure. 19: Comparison of the ANN predictions and the test results for the 12 days' energy consumption, Optimized SCSGB, sequence test results.

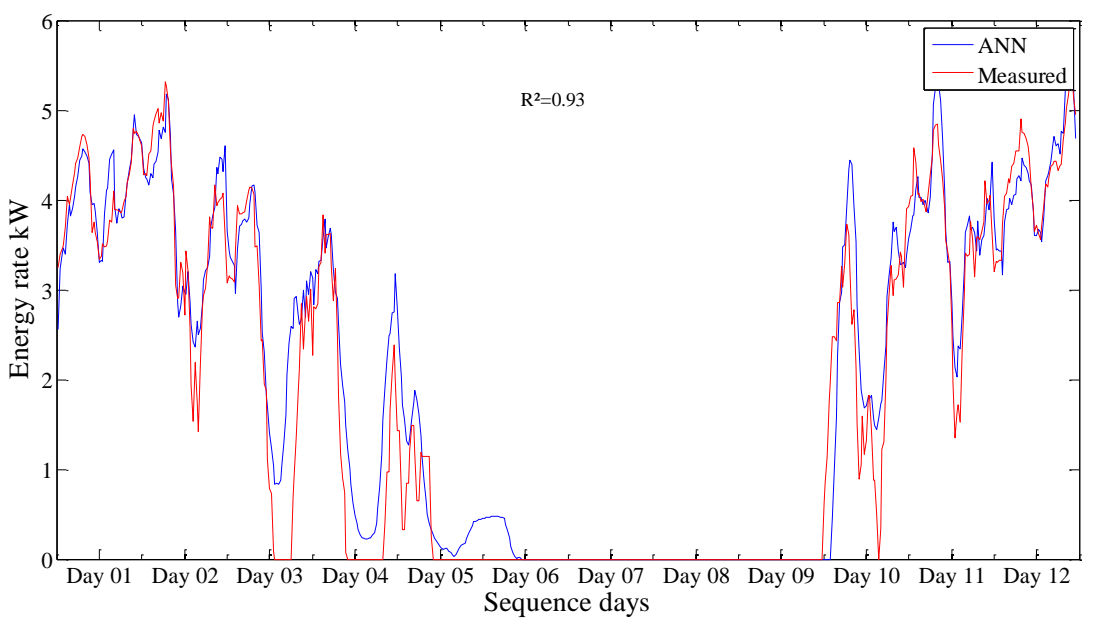

Figure. 20: ANN1 and TRNSYS outputs for the "Zurich SFH100 $16 \mathrm{~m}^{2}$ " environment, Optimized SCSGB.

An example of the recorded and simulated energy rate is presented in Figure 20. Except at certain times, the ANN predictions are on the whole very representative of the actual changes overall. The methodology developed herein aims to be a global methodology that gives satisfactory energy consumption estimations of any system. Therefore, it is not mandatory to have very accurate energy rate predictions. In system monitoring problems, the model's accuracy as a function of time is crucial. This requires that the models not be simulated; they are used to make $k$-ahead step predictions. This means that the model uses $k$ real past values to predict the future values. In the present study, ANN models are simulated, as mentioned in section 3.3.6. 


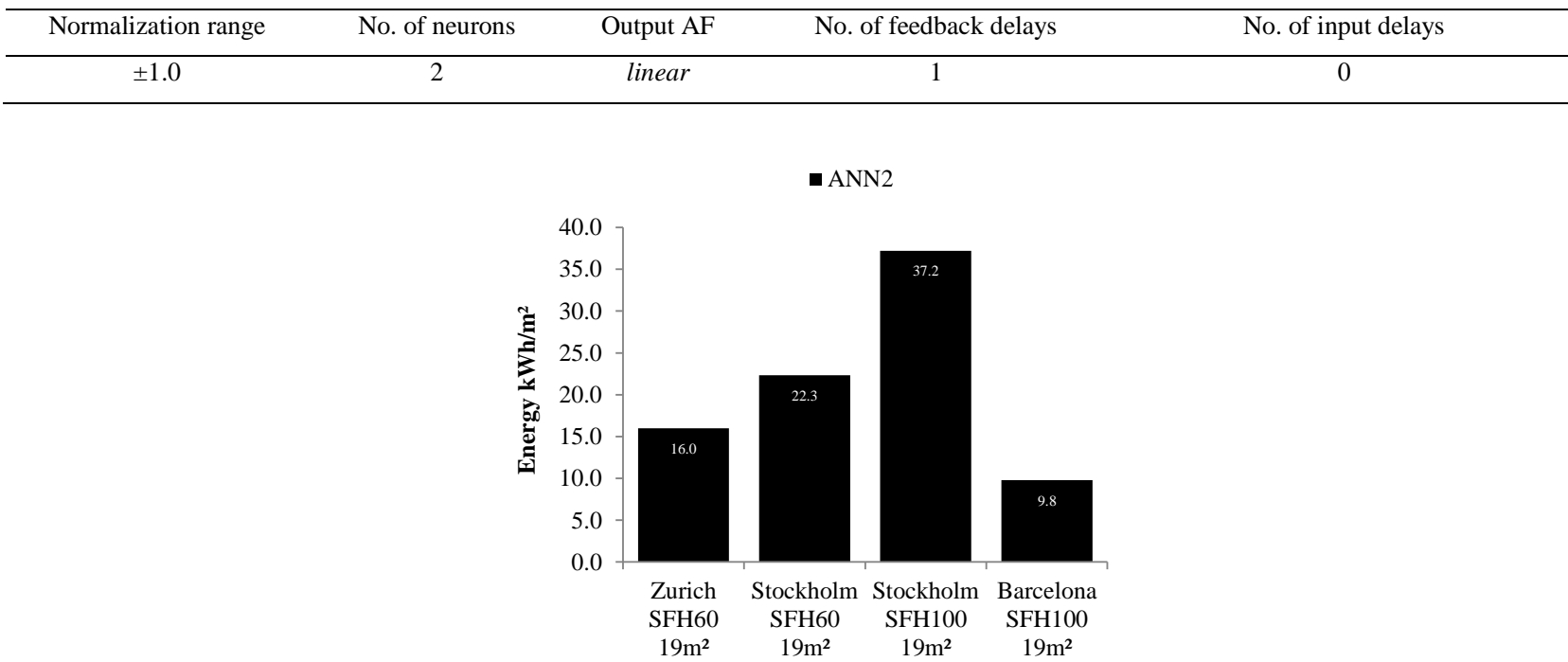

Figure. 21: Example of the methodology application. Annual ANN predictions for energy consumption of the real system SCSWSHP tested in the semivirtual test bench.

Table 6 presents the characteristics of the selected model of the tested SCS combined with water source HP. This system is not the one simulated in section 4.1.1. The neural model was used to simulate the system's dynamic behaviour in different conditions. ANN predictions are presented in Figure 21. ANN estimations are realistic. They are the same order of magnitude as the SCS water source HP model (as in Figure 14).

For the sake of completeness, ANN model predictions should be compared to annual real in situ measurements of different systems on different climates, building types and collector areas. However, this study would require much more time to be completed.

\section{Conclusion and perspectives}

In the present paper, the results of the development of a new generic methodology to model thermal energy systems for building applications are presented. This can be applied to systems as found on the market, obviating the need to dismantle the system in order to characterize it. The ANN models developed are able to predict, with a good level of precision, the annual consumption of three different types of system based on a short learning sequence test lasting only 12 days. In fact, the ANN generalization ability makes possible to predict the system's behaviour in various environments (other climate types and other building types), different from the environment used during the ANN learning process. Prediction errors are in most cases within the range of $\pm 10 \%$ for non-extreme boundary conditions. The proposed approach will be helpful in the context of energy performance guarantees. Moreover, ANN annual simulation takes only a few seconds. This is ideal for engineers and designers to compare different solutions and select the system most suitable for a given building and location. The methodology is completely objective; it could be used by non-experts because its application consists only on testing the system and applying the developed training algorithm.

Neural network limitations appear in conditions that are very different from those used in training. In fact, ANN predictions are poor for boundary conditions that are very different from the condition used during the physical test.

Future work will concentrate on the development of an optimal method to build up the learning data set. Using data from different climates and conditions seems to be relevant. This certainly will improve the generalization ability of the neural model and might 
534 cooling function and ventilation as well. The specific features of ANN energy predictions for each system will also be studied.

535 This could determine, for instance, corrective operations to be integrated into the methodology in order to improve the accuracy of 536 the estimations further.

\section{Acknowledgments}

538 This study has been supported and funded by the French Agency for Environment and Energy Management (ADEME), the 539 National Institute of Nuclear Sciences and Techniques (INSTN) and the European Union's Seventh Framework Program 540 FP7/2007-2011 under grant agreement no 282825 - Acronym MacSheep.

\section{References}

[1] Z. Xingxing, Z. Xudong, S. Jingchun, X. Jihuan and Y. Xiaotong, "Dynamic performance of a novel solar photovoltaic/loopheat-pipe heat pump system," Applied Energy, vol. 114, p. 335-352, 2014.

[2] W. Wei, Y. Tian, W. Baolong, S. Wenxing and L. Xianting, "Simulation of a combined heating, cooling and domestic hot water system based on ground source absorption heat pump," Applied Energy, vol. 126, p. 113-122, 2014.

[3] K. Kaygusuz, "Performance of Solar-Assisted Heat-Pump Systems," Applied Energy, vol. 51, no. 2, p. 93-109, 1995.

[4] C. Xi and Y. Hongxing, "Performance analysis of a proposed solar assisted ground coupled heat pump system," Applied Energy, vol. 97, p. 888-896, 2012.

[5] C. Xi, L. Lin and Y. Hongxing, "Long term operation of a solar assisted ground coupled heat pump system for space heating and domestic hot water," Energy and Buildings, vol. 43, no. 8, p. 1835-1844, 2011.

[6] H. Li and H. Yang, "Study on performance of solar assisted air source heat pump systems for hot water production in Hong Kong," Applied Energy, vol. 87, no. 9, p. 2818-2825, 2010.

[7] M. Leckner and R. Zmeureanu, "Life cycle cost and energy analysis of a Net Zero Energy House with solar combisystem," Applied Energy, vol. 88, no. 1, p. 232-241, 2011.

[8] A. Žandeckis, L. Timma, D. C. Rochas and M. Rošā, "Solar and pellet combisystem for apartment buildings: Heat losses and efficiency improvements of the pellet boiler," Applied Energy, vol. 101, p. 244-252, 2013.

[9] S. R. Asaeea, V. I. Ugursala, I. Beausoleil-Morrisonb and N. Ben-Abdallahc, "Preliminary study for solar combisystem potential in Canadian houses," Applied Energy, vol. 130, p. 510-518, 2014.

[10] M. Missouma, A. Hamidatb and L. Loukarfia, "Energetic Performance Analysis of a Solar Combisystem. Application to a Rural House in Chlef Region (Algeria)," Energy Procedia, vol. 50, p. 512-519, 2014.

[11] P. Papillon, "Combisol project: Solar Combisystems Promotion and Standarisation," 2011. [Online]. Available: http://solarthermalworld.org/content/combisol-project-solar-combi-systems-are-gaining-market-share. [Accessed 27 January 2015].

[12] M. Y. Haller and D. Carbonell, "Solar and heat pump systems - summary of simulation results of the IEA SHC TASK 44/ HPP Annex 38," in IEA Heat pump conference, montréal, 2014.

[13] J.-J. Wang, Y.-Y. Jing, C.-F. Zhang and Z. (. Zhai, "Performance comparison of combined cooling heating and power system in different operation modes," Applied Energy, vol. 88 , p. 4621-4631, 2011.

[14] M. Albaric, B. Mette, J. Ullman, H. Drück and P. Papillon, "Comparison of two different methods for solar combisystems performance testing," in Eurosun conference, Graz, 2010.

[15] M. Goldsworthya et S. Whitea, «A Component Testing System Simulation (CTSS) method for characterising solar airconditioner performance,» International Journal of Refrigeration, vol. 39, p. 160-171, 2014.

[16] M. Kabariti and Y. Mowafi, "Testing and evaluation of thermosyphon solar water heating system by means of components testing and whole system testing and simulation in Jordan," Renewable Energy, vol. 9, no. 1-4, pp. A594, 595-599, 1996.

[17] P. Frey, S. Fischer and H. Drück, "Artificial Neural Network modelling of sorption chillers," Solar Energy, vol. 108, p. 525537, 2014. 
[18] J. Facão and M. J. Carvalho, "New test methodologies to analyse direct expansion solar assisted heat pumps for domestic hot water," Solar Energy, vol. 100, pp. 66-75, 2014.

[19] D. Menegona, A. Vittoriosia and R. Fedrizzia, "A new test procedure for the dynamic laboratory characterization of thermal systems and their components," Energy and Buildings, vol. 84, p. 182-192, 2014.

[20] I. Malenković and E. M. Serrats, "Revirw on Testing and Rating Procedures for Solar Thermal and Heat Pump Systems and Components, Technical Report 5.1.2, part of Deliverable 5.1 of the project QAiST - Quality Assurance in Solar,” 2012. [Online]. Available: http://www.estif.org/solarkeymarknew/projects/qaist. [Accessed 4 February 2015].

[21] S. Joshi, R. Bokil and J. Nayak, “Test standards for thermosyphon-type solar domestic hot water system: review and experimental evaluation,” Solar Energy, vol. 78, no. 6, p. 781-798, 2005.

[22] C. Bales, «Combitest - A New Test method for Thermal Stores Used in Solar Combisystems (PhD Thesis),» Building Services Engineering Department of Building Technology Chalmers University Of Technology, Göteborg, 2004.

[23] M. Haller, R. Haberl, T. Persson, C. Bales, P. Kovacs, D. Chèze and P. Papillon, "Dynamic whole system testing of combined renewable heating systems - The current state of the art," Energy and Buildings, vol. 66, pp. 667-677, 2013.

[24] I. S. ISO9459-5, "Solar Heating. Domestic hot water. Part 5: System performance characterization by means of wholesystem tests and computer simulation," 2007.

[25] G. Panaras, E. Mathioulakis and V. Belessiotis, "A method for the dynamic testing and evaluation of the performance of combined solar thermal heat pump hot water systems," Applied Energy, vol. 114, pp. 124-134, 2014.

[26] P. Almeidaa, M. J. Carvalho, R. Amorim, J. F. Mendes and V. Lopes, "Dynamic testing of systems-use of TRNSYS as an Approach for Parameter Identification," Solar Energy, vol. 104 , p. 60-70, 2014.

[27] A. Leconte, "Identification de caractéristiques réduites pour l'évaluation des performances des systèmes solaires combinés (PhD thesis)," Savoy university, Bourget du Lac, 2011.

[28] Eur'Observ'ER, "Solar Thermal and Concentrated Solar Power Barometer," May 2013. [Online]. Available: http://www.energies-renouvelables.org/observ-er/stat_baro/observ/baro215.pdf. [Accessed 2015].

[29] M. D. Schicktanz, C. Schmidt and R. Fedrizzi, "Classification of rating methods for solar heating and cooling systems," Energy Procedia, vol. 48, pp. 1676-1687, 2014.

[30] A. Leconte, G. Achard et P. Papillon, «Global approach test improvement using a neural network model identification to characterise solar combisystem performances,» Solar Energy, vol. 86, pp. 2001-2016, 2012.

[31] M. Wetter and A. Huber, "TRNSYS Type 451 - Vertical Borehole Heat Exchange Model," 1997. [Online]. Available: Www.transsolar.com.

[32] M. Albaric, J. Nowag and P. Papillon, "Thermal performance evaluation of solar combisystems using a global approach," in Eurosun conference, Lisbon, 2008.

[33] R. Heimrath and M. Haller, "Project Report A2 of Subtack A: The reference heating system, the template solar system. A report of IEA SHC - Task 32," 2007.

[34] G. Cybenko, "Approximation by Superpositions of a Sigmoidal Function," Math. Control Signals Systems, vol. 2, pp. 303$314,1989$.

[35] S. A. Kalogirou, "Applications of artificial neural networks for energy systems," Applied Energy, vol. 67, pp. 17-35, 2000.

[36] S. A. Kalogirou, "Long-term performance prediction of forced circulation solar domestic water heating systems using artificial neural networks," Applied Energy, vol. 66, pp. 63-74, 2000.

[37] M. Mohanraj, S. Jayaraj and C. Muraleedharan, "Performance prediction of a direct expansion solar assisted heat pump using artificial neural networks," Applied Energy, vol. 86, pp. 1442-1449, 2009.

[38] S. Kalogirou, E. Mathioulakis and V. Belessiotis, "Artificial neural networks for the performance prediction of large solar systems," Renewable Energy, vol. 63, pp. 90-97, 2014.

[39] C. Burattia, M. Barbanerab and D. Palladinoa, "An original tool for checking energy performance and certification of buildings by means of Artificial Neural Networks," Applied Energy, vol. 120, p. 125-132, 2014.

[40] S. Rosiek and F. Batlles, "Performance study of solar-assisted air-conditioning system provided with storage tanks using artificial neural networks," International Journal of Refrigeration, vol. 34, pp. 1446-1454, 2011.

[41] W. Gang and J. Wang, "Predictive ANN models of ground heat exchanger for the control of hybrid ground source heat pump systems," Applied Energy, 2013. 
[42] M. Kljajic, D. Gvozdenac and S. Vukmirovic, "Using neural networks for modeling and predicting boiler's operationg performance," Energy, vol. 45, pp. 304-311, 2012.

[43] P. Vig and I. Farkas, "Neural network Modeling of thermal stratification in a solar DHW storage," Solar Energy, vol. 84, pp. 801-806, 2010.

[44] Y. O. Ozgoren, S. Cetinkaya, S. Saridemir, C. Adem and F. Kara, "Predictive modeling of performance of a helium charged Stinrling engine using and artificial neural network," Energy conversion and Management, vol. 67, pp. 357-368, 2013.

[45] K. Ghorbanian and M. Gholamrezaei, "An artificial neural network approach to compressor performance prediction," Applied Energy, vol. 86, no. 7-8, p. 1210-1221, 2009.

[46] A. Sözena and A. Akçayolb, "Modelling (using artificial neural-networks) the performance parameters of a solar-driven ejector-absorption cycle," Applied Energy, vol. 79, no. 3, p. 309-325, 2004.

[47] G. Dreyfus, Neural networks methodology and applications, Springer, 2005.

[48] M. Norgaard, O. Ravn, N. Poulsen and L. Hansen, Neural networks for modelling and control of dynamic systems, Springer, 2000.

[49] D. Marquardt, "An Algorithm for Least-Squares Estimation of Nonlinear Parameters," SIAM Journal on Applied Mathematics, vol. 11, no. 2, p. 431-441, 1963.

[50] A. Lazrak, A. Leconte, G. Fraisse, P. Papillon and B. Souyri, A solar combisystem input-output modelling: exploration of several algorithms and learning procedures, Rabat, 2014, p. 10.

[51] D. Nguyen and B. Widrow, "Improving the learning speed of 2-layer neural networks by choosing initial values of the adaptative weights," Proceeding of the International Joint Conference on Neural Networks, vol. 3, pp. 21-26, 1990.

[52] D. MacKay, "Bayesian interpolation," Neural Computation, vol. 4, no. 3, pp. 415-447, 1992.

[53] A. Lazrak, A. Leconte, G. Fraisse, p. Papillon and B. Souyri, Vers une méthodologie générique de modélisation par réseaux de neurons des systèmes énergétiques dans le bâtiment, Arras, 2014, p. 8.

[54] X. He and H. Asada, A new method for identifying orders of input-output models for nonlinear dynamic systems, San Francisco, 1993, pp. 2520-2523.

[55] K. Gnana Sheela and D. N. S., "Review on Methods to Fix Number of Hidden Neurons in Neural Networks," Mathematical Problems in Engineering, vol. 2013, no. Article ID 425740, 2013.

[56] B. Widrow and M. Lehr, "30 Years of Adaptive Neural Networks: Perceptron, Madaline, and Backpropagation," Proceedings of the IEEE, vol. 78, no. 9, pp. 1415-1442, 1990.

[57] S. Lawrence, C. L. Giles and A. C. Tsoi, "What Size Neural Network Gives Optimal Generalization? Convergence Properties of Backpropagation," Institute for Advanced Computer Studies, University of Maryland, College Park, 1996.

[58] M. Qia and G. P. Zhangb, "An investigation of model selection criteria for neural network time series forecasting," European Journal of Operational Research, vol. 132, no. 3, p. 666-680, 2001.

[59] A. Khosravi, Nahavandi, D. Creighton and Saeid, "Quantifying uncertainties of neural network-based electricity price forecasts," Applied Energy, vol. 112, p. 120-129, 2013.

[60] MacSheep, "MacSheep - New Materials and Control for a next generation of compact combined Solar and heat pump systems with boosted energetic and exergetic performance," 2012-2015. [Online]. Available: http://macsheep.spf.ch/Project.248.0.html. [Accessed 2014]. 